\title{
Genetic mapping and identification of new major loci for tolerance to low phosphorus stress in rice
}

\author{
Abdul Malik Solangi ${ }^{1}$ (1) - Hira Khanzada $^{1}$ (D) Ghulam Mustafa Wassan $^{1}$ (1) \\ Adnan Rasheed ${ }^{1} \cdot$ Ayaz Ali Keerio $^{2}\left({ }^{2} \cdot\right.$ Majeeduddin Solangi $^{2} \cdot$ Saba Khanzada $^{1,2}$. \\ Muhammad Faheem ${ }^{2} \cdot$ Jianmin Bian $^{1} \cdot$ Xiaohua Pan $^{1} \cdot$ Rui Cai Han ${ }^{1}$. \\ Xunfeng $\mathrm{He}^{1} \cdot$ Ziming $\mathrm{Wu}^{1}$
}

Received: 17 August 2019/Revised: 24 December 2019/Accepted: 30 July 2020/Published online: 17 August 2020

(C) The Author(s) 2020

\begin{abstract}
Phosphorus (P) is one of the essential macronutrients for rice. In this study, we used 120 rice backcross recombinant inbred lines (BRILs) derived from a cross indica $c v$. Changhui 891 and japonica $c v$. 02428. To elucidate the genetic control of $\mathrm{P}$ deficiency tolerance in rice, we have used high quality SNPs bin markers to identify some important loci underlying phosphorus deficiency. The bin map was generated which includes 3057 bins covering distance of $1266.5 \mathrm{cM}$ with an average of $0.41 \mathrm{cM}$ between markers. Based on this map, 50 loci, including four novel loci, $q S L-3, q R L-11, q S D W-1, q R D W$ 1 with phenotypic variance $23.26 \%, 12.06 \%, 9.89 \%$ associated with $\mathrm{P}$ deficiency-related seedling traits were
\end{abstract}

Abdul Malik Solangi, Hira Khanzada and Ghulam Mustafa Wassan have contributed equally to this work.

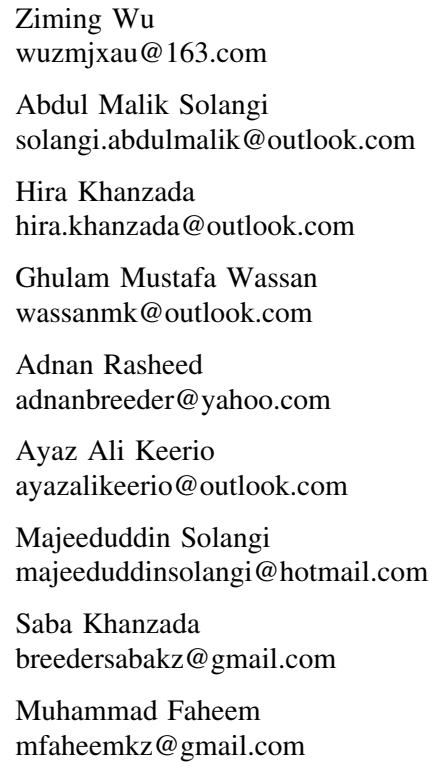

identified. No significant QTLs was found for root length under $\mathrm{P}+$, shoot fresh weight $\mathrm{P}-$ and root length, shoot fresh weight for $\mathrm{P}+, \mathrm{P}-$ and their ratio respectively. Root fresh weight, and root dry weight were strongly correlated to each other, and QTLs for these variables were located on the same chromosome 1 at the same region. Notably, 3 pleiotropic regions is the pioneer of our study, and these regions would facilitate map-based cloning to expedite the MAS selection for developing low phosphorous tolerant varieties. This study not only improves our knowledge about molecular processes associated with $\mathrm{P}$ deficiency, but also provides useful information to understand the genetic architecture of low phosphorous tolerance.
Jianmin Bian

jmbian81@126.com

Xiaohua Pan

xhuapan@163.com

Rui Cai Han

hrc1988113@163.com

Xunfeng $\mathrm{He}$

704365587@qq.com

1 Key Laboratory of Crop Physiology, Ecology and Genetic Breeding, Ministry of Education, College of Agronomy, Jiangxi Agricultural University, Nanchang 330045, Jiangxi, People's Republic of China

2 Faculty of Crop Production, Sindh Agriculture University Tando Jam, Sindh, Pakistan 
Keywords Rice - Backcross recombinant inbreed lines . Single nucleotide polymorphism · QTL analysis · Seedling traits · Low phosphorus

$\begin{array}{ll}\text { Abbreviations } \\ \text { BRILs } & \text { Backcross recombinant inbreed lines } \\ \text { QTLs } & \text { Quantitative trait loci } \\ \text { SNP } & \text { Single nucleotide polymorphism } \\ \text { cm } & \text { Centimeter } \\ \text { cM } & \text { Centimorgan } \\ \text { mg } & \text { Milligram } \\ \text { SL } & \text { Shoot length } \\ \text { RL } & \text { Root length } \\ \text { SFW } & \text { Shoot fresh weight } \\ \text { RFW } & \text { Root fresh weight } \\ \text { SDW } & \text { Shoot dry weight } \\ \text { RDW } & \text { Root dry weight } \\ \text { P } & \text { Phosphorus } \\ \text { MAS } & \text { Marker assisted selection }\end{array}$

\section{Introduction}

Phosphorus (P) is an essential macro-element for the plant growth and development. It is associated with biological components and soil chemicals that make it important in growing plants (Richardson et al. 2009). It endorses plant growth from root development, early flowering, and seed ripening. Mainly, it is imperative at the early plant growth stages as the plant is recovering from the transplanting shock (Dobermann 2000). However, phosphorus deficiency is a major obstacle for plant development and growth. About half of the agricultural land in Asian, African, and South American countries are facing phosphorus deficiency (Lynch 2011). Moreover, it engenders a series of physiological and molecular processes that led to severe yield losses (Dobermann 2000; Ismail et al. 2007). Besides aforementioned, it is the secondary cause of the low soil $\mathrm{pH}$ which forces restrictions in root development, even though there are high concentrations of iron aluminum (Ismail et al. 2007).

Rice (Oryza sativa L.) is an essential food as a diet for humans more than half of the world population. Majority of the human population directly or indirectly depends on the rice crop for their daily energy needs (Elert 2014). To meet the availability of rice for the large human community, the rice production needs to be improved by 0.6 to $0.09 \%$ in a year (Vinod and Heuer 2012). Like all other cereals, rice also requires a sufficient amount of phosphorus for vigorous and healthy plant growth and seed setting to achieve high yield. Generally, rice response to phosphorus is less studied than response to the nitrogen. Moreover, phosphorus significantly stimulates root enlargement into the new plant, capable to increase the absorbance capacity of nutrients from the soil (Dobermann 2000).

In rice, phosphorous deficient resistant varieties could be produced rapidly through the prominent strategy of Marker Assisted Breeding (Alpuerto et al. 2009). Although, genomic technologies, molecular markers and various statistical methods had significantly altered the genetic analysis of plant breeding. These approaches have provided important tools to locate genomic regions underlying abiotic stresses, including phosphorus tolerance. The physical and genomic maps allow the quantitative trait loci (QTLs) with positive/desired effects on the yield (Chao et al. 2015; Kumar et al. 2017). Rapid improvement in whole-genome sequence technology provided an efficient platform for several million single nucleotide polymorphisms (SNPs) across the genome (Jiang et al. 2017). The SNPs with the same genotype in the internal are joined into bins through a sliding window approach (Huang et al. 2009); and these bins could discriminate recombination events across the whole population and could be used as markers of choice for QTL studies in plant species (Wang et al. 2011). The development of high-density genetic maps generated by bin markers has expedited the genetic studies underlying quantitative traits in various crops (Byrne et al. 2013; Jiang et al. 2017; Poland et al. 2012; Sonah et al. 2013; Wang et al. 2015; Xie et al. 2010; Xu et al. 2010). QTL mapping is an essential strategy to assign the positions of the markers associated with the desired traits. The genome mapping can be used for identifying the QTLs associated with traits related to $\mathrm{P}$ deficiency tolerance at the seedling stage (Lin et al. 2010; Wissuwa et al. 2002, 1998; Zhang et al. 2018).

To date, many QTLs have been identified across the rice genome associated with low phosphorus tolerance. However, PSTOL1 is a major candidate gene for low phosphorus, is identified on the chromosome 12 of the rice genome, cloned from P-deficiency tolerant rice variety Kasalath (under name Pup1) (Gamuyao et al. 2012; Wissuwa et al. 2002). To investigate the genetic basis of low phosphorus at seedling stage in rice, numerous studies have been conducted and reported low phosphorus tolerant QTLs identified using different populations (Hu et al. 2001; Li et al. 2009; Lin et al. 2010; Ming et al. 2000; Ni et al. 1998). The screening and development of rice varieties that have properties of phosphorus efficiency provide an alternative and promising solution to resolve this problem, this could be achieved by the use of low phosphorus tolerant genotypes as parents in the rice breeding programs on low phosphorous tolerance (Chin et al. 2011; Wissuwa et al. 1998).

The goal of this study was to identify QTLs for low phosphorous tolerance. High resolution QTL mapping has been reported through sequencing based genotyping of 120 
rice backcross recombinant inbreed lines (BRILs). We analyzed the main effects and digenic interactions of QTLs for seedling growth traits under low phosphorus and high phosphorus stresses. The QTLs identified in this study will be valuable sources for phosphorus deficiency studies in rice.

\section{Materials and methods}

\section{Plant population}

In this study, BRILs (BC1F6) population consisting of 120 individuals derived from Changhui 891, a leading indica restorer line in south China and 02428, a prominent japonica wide compatibility variety, were used for QTL mapping for low Phosphorus. The population was developed in the experimental field at Jiangxi Agricultural University in Nanchang, Jiangxi Province, and Linwang, Hainan Province.

\section{Hydroponic experiment}

The experiment was conducted at Key Laboratory of Crop Physiology, Ecology, and Genetics Breeding Of Jiangxi Agricultural University, China. Briefly, 30-40 uniform seeds were selected from 120 BRILs along with their parental lines and surface-sterilized for $20 \mathrm{~min}$ in $1 \%(\mathrm{w} / \mathrm{v})$ sodium hypochlorite solution and then washed with distilled water, then sterilized seeds were used for germination at $28{ }^{\circ} \mathrm{C}$ for $48 / 64 \mathrm{~h}$. After germination, ten seedlings were transplanted into a PCR tube, and transferred in plastic boxes. The box contains either P-deficiency $\left(\mathrm{P}_{-}\right)$or $\mathrm{P}$-sufficiency $(\mathrm{P}+)$ aerated nutrient solution, formulation of the nutrient solution was, according to (Yoshida et al. 1971), with some modifications. The culture solution was prepared in distilled water. The nutrient solution was renewed weekly, and the normal culture solution was a mixture of $(\mathrm{mg} / \mathrm{L}) ; \mathrm{Ca}\left(\mathrm{NO}_{3}\right)_{2}, 24.8 \mathrm{KH}_{2} \mathrm{PO}_{4}, 48.2\left(\mathrm{NH}_{4}\right)_{2} \mathrm{SO}_{4}, 15.9$ $\mathrm{K}_{2} \mathrm{SO}_{4}, 65.9 \mathrm{MgSO}_{4}$ and $59.918 .5 \mathrm{KNO}_{3}$ and $1 \mathrm{~mL} / \mathrm{L}$ $\mathrm{MnCl}_{2} \cdot 4 \mathrm{H}_{2} \mathrm{O}, \quad \mathrm{CuSO}_{4} \cdot 5 \mathrm{H}_{2} \mathrm{O}, \quad \mathrm{H}_{2} \mathrm{MoO}_{4} \cdot \mathrm{H}_{2} \mathrm{O}, \quad \mathrm{H}_{3} \mathrm{BO}_{3}$, $\mathrm{ZnSO}_{4} \cdot 7 \mathrm{H}_{2} \mathrm{O}$ and Fe-EDTA. For the low phosphorus treatment, the $\mathrm{KH}_{2} \mathrm{PO}_{4}$ application reduced to $0.32(\mathrm{mg} / \mathrm{L})$. The $\mathrm{pH}$ value of solutions was adjusted to 5.0 by using $\mathrm{NaOH}$ or $\mathrm{HCl}$. A randomized complete block design with three replications was used for each experiment. All the lines and their parents were planted randomly. Seedlings were harvested 30 days after planting.

\section{Phenotypic traits measurements}

A total of six seedling traits were measured with three replicates from all of the lines under both levels of phosphorus. The phenotypic data were recorded for all traits for measuring the shoot length (SL) and root length (RL) by using a ruler. To determine the fresh weight, the seedlings were washed with water, and the shoot fresh weight (SFW), root fresh weight (RFW) were noted by using digital weight balance. For dry weight, the roots and shoots were put in craft paper envelope for drying at $65 \mathrm{C}$ for $72 \mathrm{~h}$ in an oven. The shoot dry weight (SDW) and root dry weight (RDW) were determined. All the traits were investigated for QTL analysis associated with low phosphorus tolerance, respectively.

\section{Phenotypic data analysis}

Phenotypic data were analyzed using analysis of variance (ANOVA) by Minitab v.18 software (Pennsylvania State University, PA, USA) based on general linear model at $p<0.05$ level and the means were compared using the Tukey's honest significant difference (HSD) test. Pearson's correlation, descriptive statistics, frequency distribution, and box plot analysis were carried out using the SPSS version 20 (SPSS, Chicago, IL, USA). The broad-sense heritability was calculated using the formula: $h^{2}=\mathrm{Vg}$ $(\mathrm{Vg}+\mathrm{Ve} / \mathrm{r})$, where, $(\mathrm{Vg})$ genotypic variance, (Ve) error variance and $\mathrm{r}$ is replication.

\section{QTL analysis in BRILs population for six seedling traits}

To investigate the QTLs for tolerance to low phosphorus in BRIL population, QTL IciMapping v4.1 software was used for QTL analysis, threshold LOD Value of 2.5 was applied (Bian et al. 2015; Jiang et al. 2017). QTL nomenclature was followed by the method of (McCouch 2008).

\section{Results}

\section{Phenotypic performance of 120 BRILs under $\mathrm{P}+$ and $\mathrm{P}-$ and their ratio}

Analysis of variance and broad-sense heritability among six seedling traits of 120 BRILs under both levels of phosphorus $(\mathrm{P}+$ and $\mathrm{P}-)$ are displayed in Table 1. For all the studied traits, analysis of variance showed highly significant difference among the evaluated lines which indicated the presence of large genetic variability. Interaction of lines, treatment, and line $\mathrm{x}$ treatment were found highly significant for all studied traits. Mean squares revealed significant variations among BRILs for all seedling traits. Estimates of broad sense heritability were found higher for all six traits, SL (96.71\%), RL (82.64\%), SFW (96.08\%), RFW (87.97\%), SDW (87.32\%) and RDW (63.81\%) 
Table 1 Analysis of variance and broad sense heritability of six seedling traits under $\mathrm{P}+$ and $\mathrm{P}-$ conditions

\begin{tabular}{|c|c|c|c|c|c|c|c|}
\hline Traits & SOV & Df & SS & MS & $F$-Value & $P$ Value & $h^{2}$ \\
\hline \multirow[t]{4}{*}{ SL } & Trt & 1 & 1838.62 & 1838.62 & 2465.84 & 0.000 & $96.71 \%$ \\
\hline & Lines & 119 & 2713.85 & 22.81 & 30.59 & 0.000 & \\
\hline & Trt $\times$ Lines & 119 & 724.91 & 6.09 & 8.17 & 0.000 & \\
\hline & Error & 478 & 356.41 & 0.75 & & & \\
\hline \multirow[t]{4}{*}{ RL } & Trt & 1 & 426.29 & 426.294 & 702.68 & 0.000 & $82.64 \%$ \\
\hline & Lines & 119 & 416.27 & 3.498 & 5.77 & 0.000 & \\
\hline & Trt $\times$ Lines & 119 & 546.35 & 4.591 & 7.57 & 0.000 & \\
\hline & Error & 478 & 289.99 & 0.607 & & & \\
\hline \multirow[t]{4}{*}{ SFW } & Trt & 1 & 9.2027 & 9.20272 & 1586.21 & 0.000 & $96.08 \%$ \\
\hline & Lines & 119 & 17.6059 & 0.14795 & 25.50 & 0.000 & \\
\hline & Trt $\times$ Lines & 119 & 3.9049 & 0.03281 & 5.66 & 0.000 & \\
\hline & Error & 478 & 2.7732 & 0.00580 & & & \\
\hline \multirow[t]{4}{*}{ RFW } & Trt & 1 & 0.08147 & 0.081473 & 64.39 & 0.000 & $87.97 \%$ \\
\hline & Lines & 119 & 1.24264 & 0.010442 & 8.25 & 0.000 & \\
\hline & Trt $\times$ Lines & 119 & 0.53082 & 0.004461 & 3.53 & 0.000 & \\
\hline & Error & 478 & 0.60478 & 0.001265 & & & \\
\hline \multirow[t]{4}{*}{ SDW } & Trt & 1 & 0.08891 & 0.088911 & 58.21 & 0.000 & $87.32 \%$ \\
\hline & Lines & 119 & 1.43367 & 0.012048 & 7.89 & 0.000 & \\
\hline & Trt $\times$ Lines & 119 & 0.29882 & 0.002511 & 1.64 & 0.000 & \\
\hline & Error & 478 & 0.73010 & 0.001527 & & & \\
\hline \multirow[t]{4}{*}{ RDW } & Trt & 1 & 0.023987 & 0.023987 & 211.13 & 0.000 & $63.81 \%$ \\
\hline & Lines & 119 & 0.037454 & 0.000315 & 2.77 & 0.000 & \\
\hline & Trt $\times$ Lines & 119 & 0.019216 & 0.000161 & 1.42 & 0.006 & \\
\hline & Error & 478 & 0.054306 & 0.000114 & & & \\
\hline
\end{tabular}

SL, shoot length, RL, root length, SFW shoot fresh weight, RFW, root fresh weight, SDW, shoot dry weight, RDW, root dry weight, SOV, source of variance, df, degree of freedom, SS, sum of squares, MS, mean squares, Trt, treatment, $h^{2}$ heritability indicated that all traits are highly heritable, and selection of these traits would be fruitful for successful breeding. The descriptive statistics for six seedling traits of BRILs under both levels of $\mathrm{P}+$ and $\mathrm{P}-$ are shown in Table 2. However, mean values for shoot length (SL), under $\mathrm{P}+, \mathrm{P}-$ (ranging from 8.47, 23.75 and 7.15, 19.9). Mean performance for root length (RL) under $\mathrm{P}+, \mathrm{P}-$ varied from 1.05, 5.10 and 1.94, 7.81. For shoot fresh weight, root fresh weight, shoot dry weight and root dry weight mean values under the both experimental conditions $(\mathrm{P}+, \mathrm{P}-)$ ranged from $0.20,1.23$ and $0.64,0.11 ; 0.26,0.04$ and $0.03,3.05 ; 0.03,0.30$ and $0.21,0.04$ and $0.01,0.05$ and $0.01,0.06$ respectively. However, the frequency distribution and box plot (Fig. 1 and 2) analysis showed that traits are normally distributed in the population. Skewness and Kurtosis for all six variables in BRILs were less than unit, showed a normal distribution of traits and data could be subjected to Quantitative traits loci analysis.

\section{Correlation coefficient analysis of six seedling traits}

In our study, we examined the phenotypic correlation coefficient analysis among the six seedling traits separately; under both $\mathrm{P}+, \mathrm{P}-$ level (results are presented in Table 3). Under $\mathrm{P}+, \mathrm{P}-$ condition, significant correlations were observed for all studied traits, SL, RL, SFW, RFW, SDW, and RDW with few exceptions. The results ranged from 0.14 to 0.84 under $\mathrm{P}+$, and from 0.02 to 0.92 under $\mathrm{P}$ deficient level (Table 3). Highest positive significant correlation under $\mathrm{P}+0.8446$ was observed between $\mathrm{SFW}$ and SDW while under $\mathrm{P}-$ highly significant positive correlation 0.92 was recorded among the SDW and SFW. Due to the highly significant correlation among the seedling trait, it might be possible to improve one trait through an indirect selection of other traits.

\section{QTL analysis for six seedling root traits under $\mathbf{P}+$ and $P$ - levels and their relative ratio}

In our study, we have identified a total of 50 QTLs with significant LOD value for all traits under the two P levels; 
Table 2 Descriptive statistics of six seedling traits observed under different $\mathrm{P}+$, $\mathrm{P}-$ conditions

\begin{tabular}{llllllllr}
\hline Trait & Trt & Mean & Min. & Max. & SD & CV $(\%)$ & Skewness & Kurtosis \\
\hline SL & P+ & 13.756 & 8.4700 & 23.750 & 2.43 & 17.72 & 0.7678 & 1.7536 \\
& P- & 10.530 & 7.1500 & 19.940 & 1.83 & 17.43 & 1.2254 & 4.2045 \\
RL & P+ & 2.7238 & 1.0500 & 5.1700 & 0.82 & 30.23 & 0.7678 & 1.7536 \\
& P- & 4.2889 & 1.9400 & 7.8100 & 1.34 & 31.32 & 0.5070 & -0.2600 \\
SFW & P+ & 0.5584 & 0.2000 & 1.2300 & 0.06 & 39.60 & 0.8240 & 0.3300 \\
& P- & 0.3321 & 0.1300 & 0.6400 & 0.11 & 34.97 & 0.4759 & -0.6464 \\
RFW & P+ & 0.0803 & 0.0200 & 0.2600 & 0.04 & 55.06 & 1.4549 & 2.5996 \\
& P- & 0.1355 & 0.0300 & 3.0500 & 0.27 & 201.58 & 10.171 & 106.08 \\
SDW & P+ & 0.1269 & 0.0300 & 0.3000 & 0.06 & 47.58 & 0.6682 & -0.0310 \\
& P- & 0.0873 & 0.0300 & 0.2100 & 0.04 & 47.10 & 0.5351 & -0.3927 \\
RDW & P+ & 0.0133 & 0.0100 & 0.0500 & 0.006376 & 47.91 & 2.4946 & 8.5151 \\
& P- & 0.0229 & 0.0100 & 0.0600 & 0.01 & 55.09 & 0.7443 & -0.1509 \\
\hline
\end{tabular}

SL, shoot length, RL, root length, SFW shoot fresh weight, RFW, root fresh weight, SDW, shoot dry weight, RDW, root dry weight, Trt. = Treatment, Min. = Minimum, Max. = Maximum, SD = Standard deviation, $\mathrm{CV}=$ Coefficient of variance
21 in $\mathrm{P}+, 12$ in $\mathrm{P}-$ and 17 in $\mathrm{P}+/ \mathrm{P}-$ ratio. Among six seedlings traits, no significant QTLs was found for root length under $\mathrm{P}+$, shoot fresh weight $\mathrm{P}-$ and root length, shoot fresh weight for $\mathrm{P}+, \mathrm{P}-$ and their ratio, respectively.

\section{QTL detection for P+}

A total of 21 QTLs were detected, with LOD value ranging from 2.64 to 10.81 and a portion of variance contributed by these genomic regions varied from 0.74 to $23.26 \%$ on the different chromosome for different traits (Table 4 and Fig. 3). Two QTLs of SL were identified on chromosome 3 and 6. QTLs $q S L-3$ and $q S L-6$ were mapped between marker 3-305, 3-306 which shows the phenotypic and LOD values of two QTLs were 23.26 and 7.60 and 8.24 and 2.97, respectively. Two QTLs, $q S F W-1$ was identified for SFW on the same chromosome with different position, between marker 1-72, 1-73 and 1-73, 1-74 with 2.95, 3.68, phenotypic \% and 3.32, 3.69 LOD Value, respectively. For RFW, four QTLs, $q R F W$-1were mapped. Three on chromosome 1 and one $q R F W-8$ on chromosome 8 , with different positions, phenotypic variance and LOD value of $10.56 \%, 10.81 \%$ and 3.62 and 2.86 , respectively. Single QTL, $q S D W-1$ was mapped on chromosome 1 for SDW between the marker interval 1-73, 1-74 which explained the $6.77 \%$ phenotypic variance. A total of 10 QTLs were mapped on chromosome 1 at different positions, with LOD values ranging from 8.09 to 6.25 and these QTLs showed varying degree of their contribution to total phenotypic variance by $0.85 \%$ to $0.91 \%$. One QTL, $q R D W-3$ was mapped on chromosome 3 between the flanking markers of 3-257 and 3-258 for root dry weight securing LOD value 4.66 and portion of phenotypic variance contributed by this QTL was $0.77 \%$. Chromosome 10 harboring the QTL $q R D W-10$ for root dry weight between the markers 10-1 and 10-2 with LOD value 6.90 and phenotypic variance $1.16 \%$. All traits under $\mathrm{P}+$ showed negative additive effect, which demonstrated that the value of traits had been decreased by these QTLs. Chromosome 1 harboring the QTLs for two different traits on the same position, which is an indication of the strong correlation of these traits, and these traits could be taken to improve high phosphorous tolerance. Two pleiotropic QTLs $q R F W-1$ and $q R D W-1$ were identified on the chromosome 1 controlling the RFW and RDW at the same position. Hence, chromosome 1 harboring two pleiotropic QTLs for two traits, which should be a new way to study multiple characters governed by the same locus.

\section{QTL detection for $\mathbf{P}-$}

Under the low P- condition, a total of 12 QTLs were identified with LOD value of 2.78 to 21.74 with $2.08 \%$ to $20.45 \%$ phenotypic variation (Table 5 and Fig. 4). Among these twelve QTLs, one QTL, $q S L-1$ was mapped between the marker 1-122 and 1-123 with highest phenotypic contribution of $20.45 \%$ and having 5.78 LOD value. For root length, $q R L-11$ alone QTL was mapped between the marker 11-55 and 11-56 with the LOD value of 3.30 and $12.06 \%$ phenotypic variation. For root fresh weight, eight QTLs were detected; 2 of them were on the chromosome 1 with LOD values ranging from 20.13, 3.40 and $12.06 \%$, $5.82 \%$ phenotypic variation explained. Five QTLs were mapped on chromosome 3 and one on chromosome 11. For SDW and RDW, single QTL was detected between marker 1-92-193 with 2.78 LOD score and explained the $9.89 \%$ phenotypic variation, while $q R D W-1$ mapped on the same chromosome among the bins- 1-37, 1-38 which contributed about $10.29 \%$ phenotypic variation and has 3.23 LOD value. 
Fig. 1 Phenotypic distribution of six seedling traits associated with $\mathrm{P}+$ and $\mathrm{P}-$ in BRILs.

Green color indicate the $\mathrm{P}+$ and red color indicate $\mathrm{P}-$, respectively
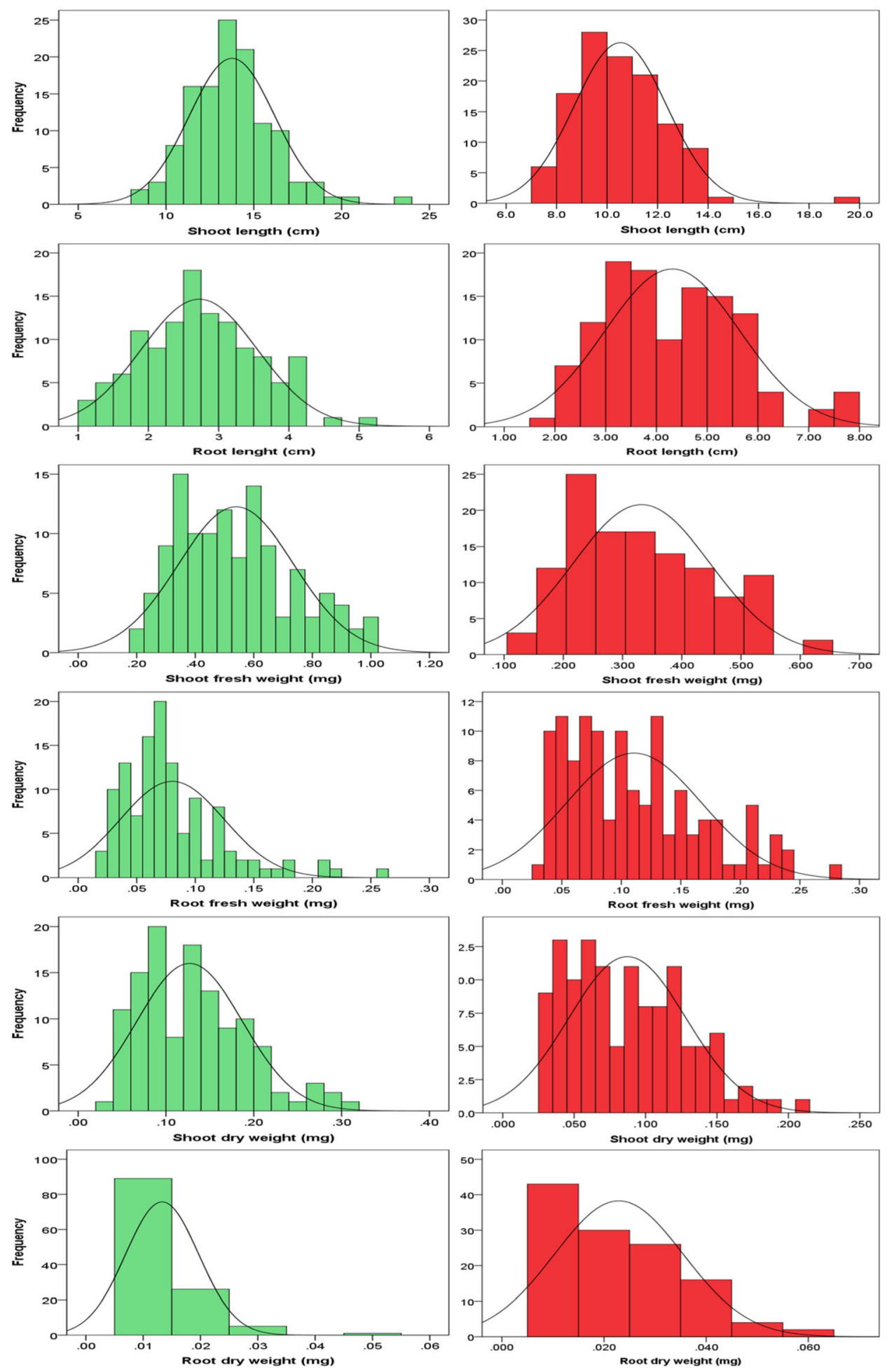

\section{QTLs detected for $\mathrm{P}+/ \mathrm{P}-$ ratio}

The ratio of $\mathrm{P}+$ and $\mathrm{P}-$ is the best strategy to investigate the putative regions involved in governing traits under low and high phosphorous stresses. Only four variables have been noted, holding a varying number of QTLs (Table 6 and Fig. 5). Total of 3 chromosomes was mapped at various regions for a total of 17 QTLs. Root length is a key factor or trait used to measure low phosphorous tolerance. Currently, only one genomic region was mapped at chromosome 11 for SL with 6.87 LOD value and $19.39 \%$ of phenotypic fraction contributed by this region. Root fresh 
SL
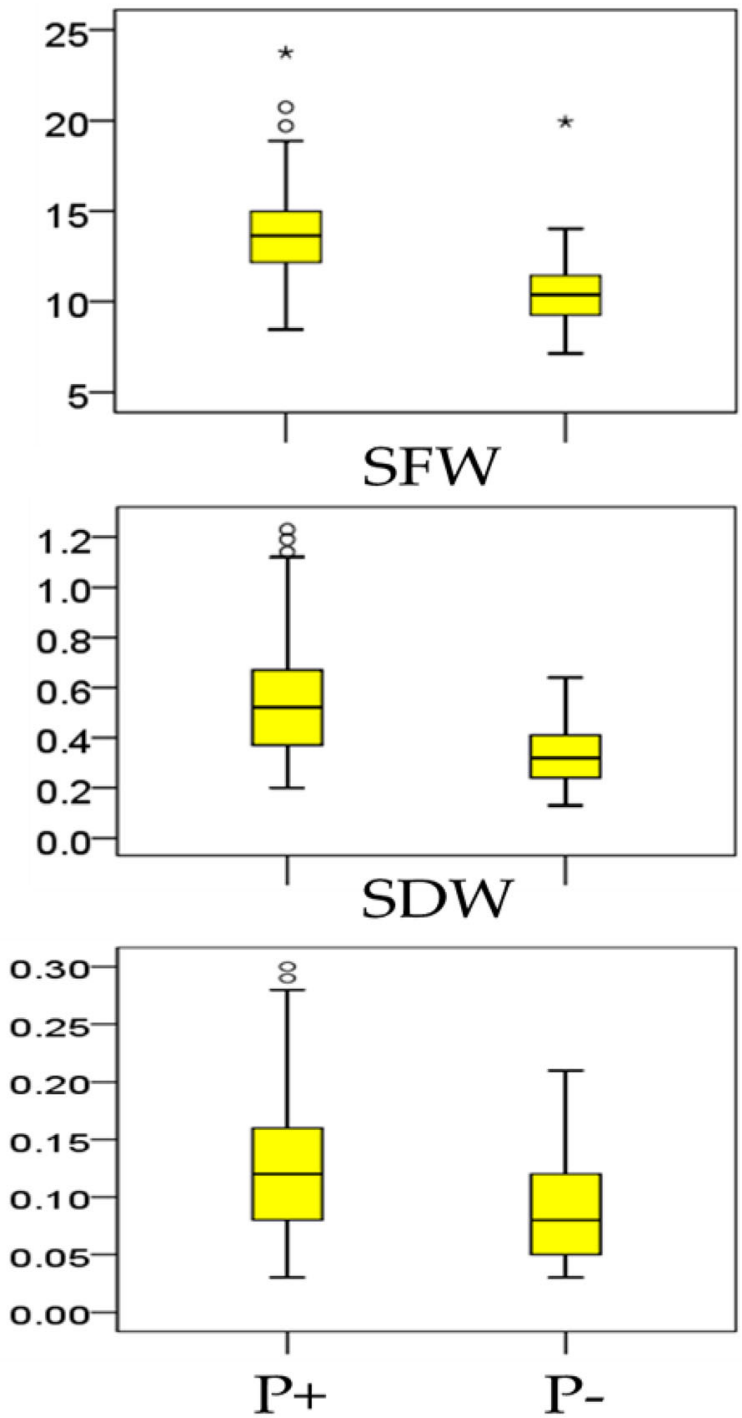

RL
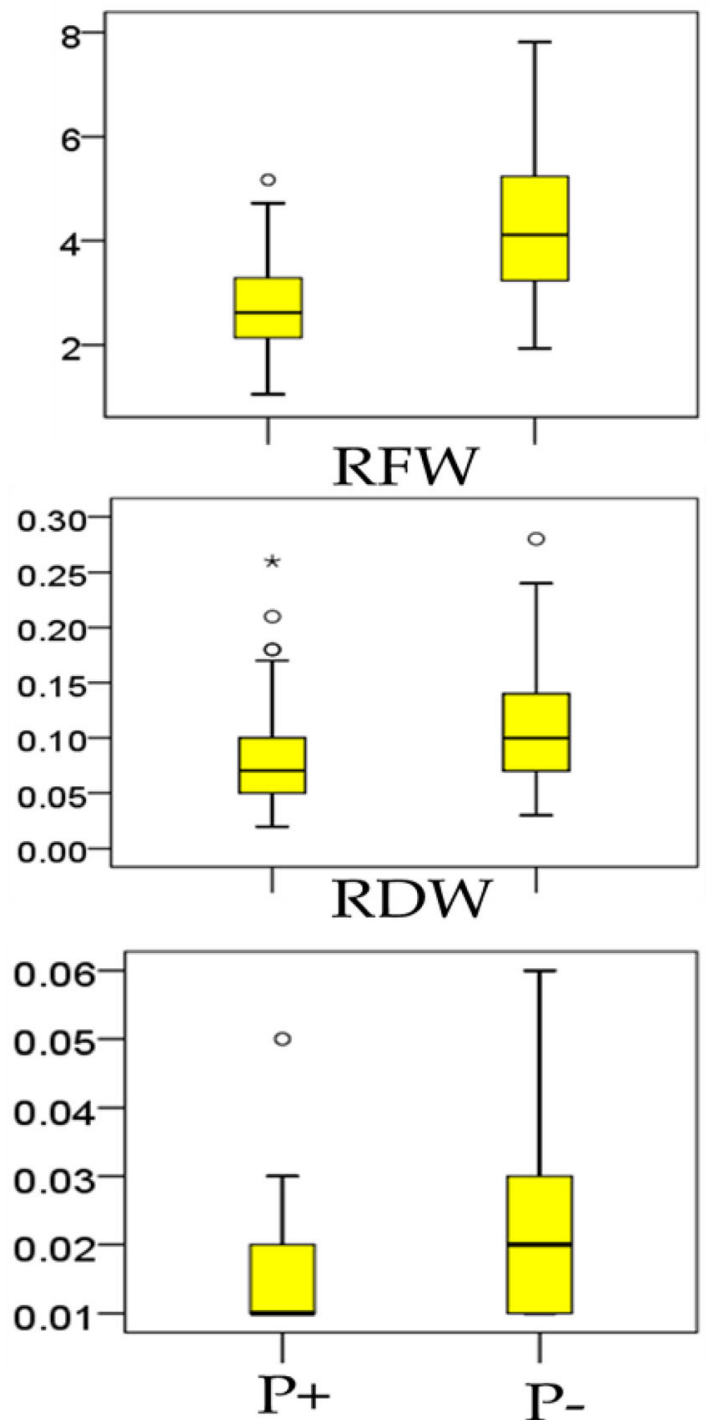

Fig. 2 Box plot analysis of six seedling traits under two phosphorus level $\mathrm{P}+$ and $\mathrm{P}-$, SL, shoot length, RL, root length, SFW shoot fresh weight, RFW, root fresh weight, SDW, shoot dry weight, RDW, root dry weight, while the circles represent outliers

Table 3 Pearson's phenotypic correlation coefficient among six seedling traits measured under $\mathrm{P}+$ and $\mathrm{P}-$ condition

\begin{tabular}{lllllll}
\hline Traits & SL & RL & SFW & RFW & SDW & RDW \\
\hline SL & 1 & $0.3637^{* *}$ & $0.4430^{* *}$ & $0.2526^{*}$ & $0.3893^{* *}$ & $0.2043^{*}$ \\
RL & $0.2537^{*}$ & 1 & $0.2545^{*}$ & $0.2838^{*}$ & $0.3748^{* *}$ & $0.1479^{*}$ \\
SFW & $0.6734 * *$ & $0.2940^{*}$ & 1 & $0.7184^{* *}$ & $0.8446^{* *}$ & $0.4895^{* *}$ \\
RFW & $0.0881^{\mathrm{NS}}$ & $0.0200^{\mathrm{NS}}$ & $0.2150^{*}$ & 1 & $0.6368^{* *}$ & $0.5280^{* *}$ \\
SDW & $0.6400^{* *}$ & $0.2187^{*}$ & $0.9222^{* *}$ & $0.2043^{* *}$ & 1 & $0.5318^{* *}$ \\
RDW & $0.4266^{* *}$ & $0.4259^{* *}$ & $0.7014^{* *}$ & $0.0728^{\mathrm{NS}}$ & $0.6856^{* *}$ & 1 \\
\hline
\end{tabular}

**Significant at $p<0.01$ and $*$ Significant at $p<0.05$. The data above the diagonal correspond to correlations among traits under high $\mathrm{P}$, while the below ones under low P stress. SL, shoot length, RL, root length, SFW shoot fresh weight, RFW, root fresh weight, SDW, shoot dry weight, RDW, root dry weight weight recorded 6 QTLs on chromosome 1, 3, and 11 with their LOD scores of $2.98-21.25$ and range of phenotypic variance showed by these regions was $2.99 \%$ to $14.84 \%$. A total of 9 QTLs $q S D W-1$ and $q S D W-3$ were distributed on 
Table 4 QTLs identified under P + for six seedlings traits in BRILs

\begin{tabular}{|c|c|c|c|c|c|c|c|c|c|c|}
\hline Trait & QTLs & $\mathrm{Chr}$ & Position & Left Marker & Right Marker & LOD & PVE (\%) & Add & Left CI & Right CI \\
\hline \multirow[t]{2}{*}{ SL } & $q S L-3$ & 3 & 880.00 & bin3-305 & bin3-306 & 7.60 & 23.26 & -2.72 & 878.50 & 881.50 \\
\hline & $q S L-6$ & 6 & 3.00 & bin6-1 & bin6-2 & 2.97 & 8.24 & 1.14 & 1.00 & 5.50 \\
\hline \multirow[t]{2}{*}{ SFW } & $q S F W-1$ & 1 & 215.50 & bin1-72 & bin $1-73$ & 3.32 & 2.95 & -0.24 & 209.00 & 221.00 \\
\hline & $q S F W-1$ & 1 & 231.50 & bin $1-73$ & bin $1-74$ & 3.69 & 3.68 & -0.23 & 224.00 & 242.00 \\
\hline \multirow[t]{4}{*}{ RFW } & $q R F W-1$ & 1 & 218.50 & bin $1-72$ & bin $1-73$ & 10.56 & 7.76 & -0.06 & 211.00 & 221.00 \\
\hline & $q R F W-1$ & 1 & 225.50 & bin $1-73$ & bin1-74 & 10.81 & 7.81 & -0.06 & 223.00 & 232.00 \\
\hline & $q R F W-1$ & 1 & 338.50 & bin1-93 & bin1-94 & 3.62 & 4.14 & -0.07 & 338.00 & 339.00 \\
\hline & $q R F W-8$ & 8 & 83.50 & bin8-32 & bin8-33 & 2.86 & 1.68 & -0.01 & 81.00 & 89.00 \\
\hline SDW & $q S D W-1$ & 1 & 228.50 & bin1-73 & bin1-74 & 2.64 & 6.77 & -0.06 & 222.00 & 240.00 \\
\hline \multirow[t]{12}{*}{ RDW } & $q R D W-1$ & 1 & 218.50 & bin1-72 & bin $1-73$ & 7.77 & 0.90 & -0.00 & 211.00 & 221.00 \\
\hline & $q R D W-1$ & 1 & 225.50 & bin $1-73$ & bin $1-74$ & 8.09 & 0.91 & -0.00 & 223.00 & 233.00 \\
\hline & $q R D W-1$ & 1 & 278.50 & bin1-77 & bin $1-78$ & 3.12 & 0.81 & -0.00 & 277.00 & 280.00 \\
\hline & $q R D W-1$ & 1 & 283.50 & bin1-78 & bin1-79 & 3.20 & 0.81 & -0.00 & 282.00 & 286.00 \\
\hline & $q R D W-1$ & 1 & 369.50 & bi1-112 & bin $1-113$ & 5.38 & 0.74 & -0.01 & 369.00 & 370.00 \\
\hline & $q R D W-1$ & 1 & 372.50 & bin1-114 & bin $1-115$ & 6.12 & 0.77 & -0.01 & 372.00 & 374.00 \\
\hline & $q R D W-1$ & 1 & 394.50 & bin1-121 & bin1-122 & 4.52 & 0.88 & -0.00 & 388.00 & 403.00 \\
\hline & $q R D W-1$ & 1 & 417.50 & bin1-122 & bin $1-123$ & 3.85 & 0.91 & -0.00 & 410.00 & 429.00 \\
\hline & $q R D W-1$ & 1 & 490.50 & bin1-142 & bin1-143 & 5.76 & 0.84 & -0.00 & 487.00 & 493.00 \\
\hline & $q R D W-1$ & 1 & 497.50 & bin $1-143$ & bin1-144 & 6.25 & 0.85 & -0.00 & 495.00 & 502.00 \\
\hline & $q R D W-3$ & 3 & 735.00 & bin3-257 & bin3-258 & 4.66 & 0.77 & -0.01 & 734.50 & 735.50 \\
\hline & $q R D W-10$ & 10 & 2.00 & bin10-1 & bin10-2 & 6.90 & 1.16 & -0.00 & 1.00 & 3.50 \\
\hline
\end{tabular}

SL, shoot length, SFW shoot fresh weight, RFW, root fresh weight, SDW, shoot dry weight, RDW, root dry weight, Chr, chromosome, LOD, logarithm of odds, PVE (\%), percent of variance explained (\%), Add, Additive effect, CI, confidence interval

chromosomes 1 and 3 for SDW securing LOD score 5.28-5.49 with $3.32-3.25$ portion of phenotypic variation shared by these loci. The genomic region on chromosome 3 harboring the QTL $q R D W-3$ for root dry weight among the flanking markers 3-254, 3-255. Chromosome 3 harboring one pleiotropic QTL qSDW-3 involved in controlling two traits at the same position and flanked by the same markers.

\section{Discussion}

Rice growth is severely affected by low phosphorus in rice growing areas. High-resolution mapping population is a basic need for any breeding scheme to identify the regions controlling traits of rice grown under low phosphorus conditions. Many populations such as chromosome segment substitution lines (CSSLs), recombinant inbred lines (RILs), near-isogenic lines (NILs) and introgression lines (ILs) have been widely studied to investigate the genetic analysis for abiotic stresses in crops. However, because of the several limitations, these cause hindrance to examine the results more accurately. CSSLs and NILs were used mainly for studying rice tolerance to low phosphorous, but these populations consume more time and increase labor cost, and these populations are overlooked under such conditions. Currently, we have used a set of 120 BRILs to get a clear clue about the targeted regions on chromosomes. Use of BRIL population gives a comprehensive understanding of QTLs governing traits under different phosphorus levels. Many studies have been conducted earlier to identify the QTLs using different P levels (Anis et al. 2018; Wang et al. 2014).

In the current study, we have evaluated a set of 120 BRILs derived from a cross between Japonica (cv.02428) and Indica (Changhui/891) background parents using a linkage map constructed by SNP markers. Therefore, we assume this population will serve as a better choice for mapping and studying important quantitative traits in rice. QTL analysis was conducted for six seedling traits under two $\mathrm{P}$ levels ( $\mathrm{P}-$ as deficiency and $\mathrm{P}+$ as sufficiency). An ideal way to measure the tolerance degree is to grow the crops in the best nutrient solution. We have focused on shoot length because of its simple measurement in response to P- stress. Shoot and root traits has been studied earlier for measuring low P- tolerance (Anis et al. 2018; Li et al. 2009). We have identified 3 QTLs $q S L-1, q S L-3, q S L-6$ for 
Fig. 3 Chromosomal location of putative QTLs for seedling traits associated with $\mathrm{P}+$. The QTLs displayed in square box, indicates the pleotropic QTLs on chromosome 1

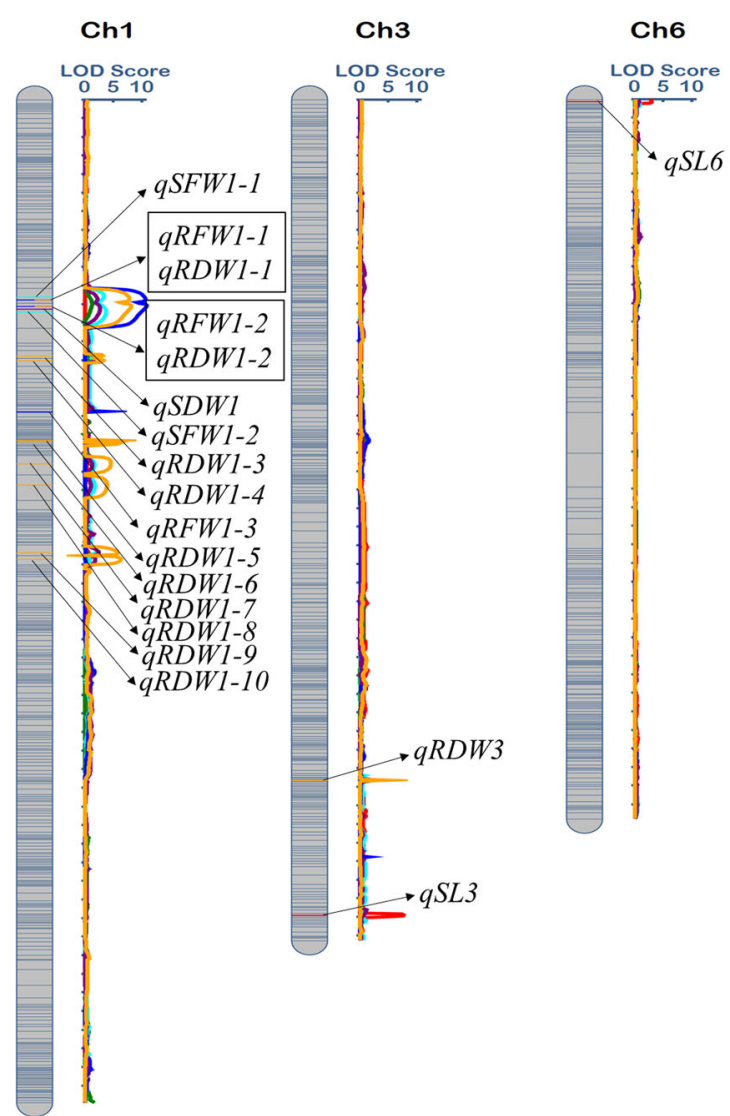

Ch10

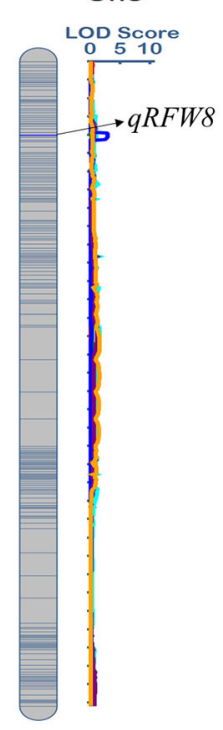

LOD Score

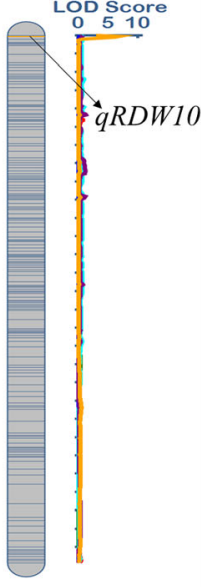

Table 5 QTLs identified under P- for six seedling traits in BRILs

\begin{tabular}{llrlllrrrrr}
\hline Trait & QTLs & Chr & Position & Left Marker & Right Marker & LOD & PVE (\%) & Add & Left CI & Right CI \\
\hline SL & $q S L-1$ & 1 & 406.50 & bin1-122 & bin1-123 & 5.78 & 20.45 & -1.86 & 396.00 & 414.00 \\
RL & $q R L-1$ & 11 & 235.50 & bin11-55 & bin11-56 & 3.30 & 12.06 & -0.87 & 232.00 & 240.00 \\
RFW & $q R F W-1$ & 1 & 338.50 & bin1-93 & bin1-94 & 20.13 & 5.82 & -0.93 & 336.00 & 339.00 \\
& $q R F W-1$ & 1 & 372.50 & bin1-114 & bin1-115 & 3.40 & 2.27 & 0.58 & 372.00 & 374.00 \\
& $q R F W-3$ & 3 & 735.00 & bin3-257 & bin3-258 & 16.8 & 5.82 & -0.93 & 734.50 & 735.50 \\
& $q R F W-3$ & 3 & 737.00 & bin3-258 & bin3-259 & 12.84 & 5.55 & -0.64 & 736.50 & 737.50 \\
& $q R F W-3$ & 3 & 768.00 & bin3-275 & bin3-276 & 13.79 & 5.91 & 0.54 & 765.50 & 769.50 \\
& $q R F W-3$ & 3 & 771.00 & bin3-276 & bin3-277 & 11.31 & 5.91 & 0.54 & 770.50 & 772.50 \\
& $q R F W-3$ & 3 & 817.00 & bin3-289 & bin3-290 & 3.40 & 2.08 & 0.39 & 815.50 & 818.50 \\
& $q R F W-11$ & 11 & 511.50 & bin11-139 & bin11-140 & 21.74 & 10.74 & -0.74 & 510.00 & 515.00 \\
SDW & $q S D W-1$ & 1 & 333.50 & bin1-92 & bin1-93 & 2.789 & 9.89 & -0.03 & 332.00 & 335.00 \\
RDW & $q R D W-1$ & 1 & 471.50 & bin1-137 & bin1-138 & 3.23 & 10.29 & -0.01 & 471.00 & 475.00 \\
\hline
\end{tabular}

SL, shoot length, RL, root length, RFW, root fresh weight, SDW, shoot dry weight, RDW, root dry weight, Chr, chromosome, LOD, logarithm of odds, PVE (\%), percent of variance explained (\%), Add, Additive effect, CI, confidence interval

shoot length, one in $\mathrm{P}$ - and two under $\mathrm{P}+$ on the chromosomes number 1 and 3. QTL $q S L-1$ was marked among the markers 1-22 and 1-23, explained the phenotypic variance of this QTL which was $20.45 \%$ while QTLs under normal $\mathrm{P}$ level was mapped on chromosome 3 between different bins 3-305, 3-306 and 3-1, 3-2 with 23.26 and $8.24 \%$ of phenotypic variation was showed by these QTLs. The QTL $q S L-3$ showed the highest percentage of variance $23.26 \%$, which showed its larger effect on the shoot length. One of our identified QTL $q S L-6$ was reported on the same 
Fig. 4 Chromosomal location of putative QTLs for seedling traits associated with low $\mathrm{P}-$ stress
Ch1

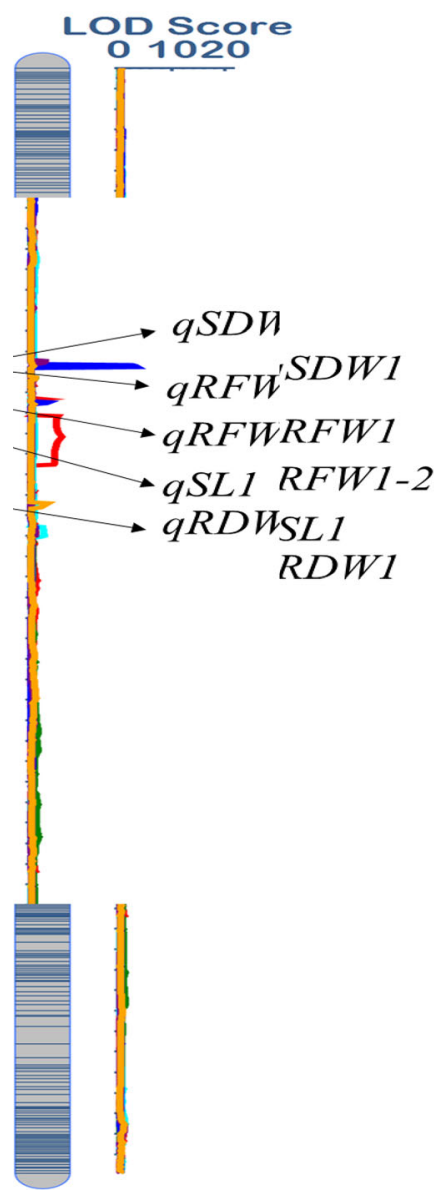

Ch3

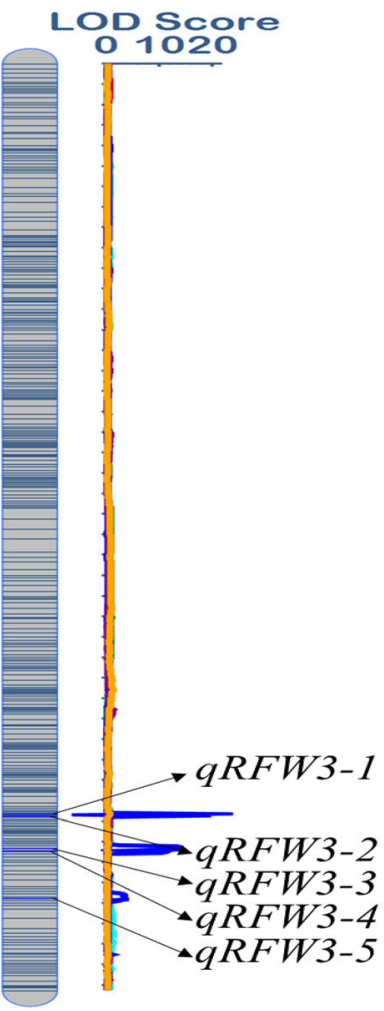

Ch11

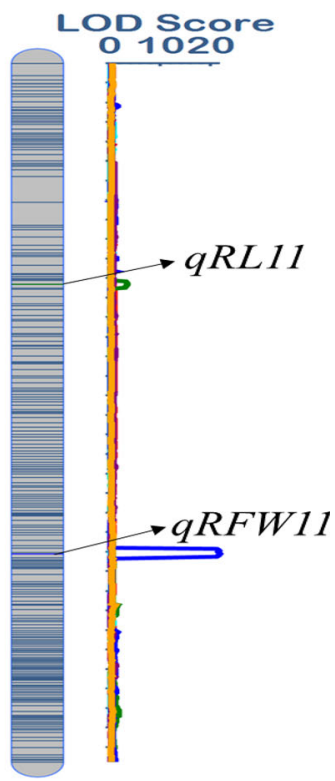

chromosome (Anis et al. 2018; Li et al. 2009; Ming et al. 2000). Another researcher, Yugandhar et al. (2017) identified QTL $q S L-1$ on chromosome 1 in rice grown under low P similar to our studies.

However, we mapped one QTL on different chromosome 3, differed from their studies, which introduced a new theory of using these regions for detection of more QTLs in the future. However, not any significant QTL for shoot length was detected under $\mathrm{P}+/ \mathrm{P}-$ conditions beside root length, shoot length also considered as an important trait for low phosphorous tolerance. Two QTLs, $q R L-11$ were detected on the same chromosome 11 at different positions in $\mathrm{P}-$ and $\mathrm{P}+/ \mathrm{P}-$ conditions. QTL $q R L-11$ was marked between 11 and 55, 11-56 bins with 3.30 of LOD value and $12.06 \%$ phenotypic variance reported root length along with $6.87 \%$ of phenotypic variance, 6.87 LOD value for QTL $q R L-11$ mapped on same chromosome 11 among the marker $11-47,11-48$ bins under $\mathrm{P}+/ \mathrm{P}-$ levels. Zhang et al. (2006) reported three QTLs for root length, one of them correspond to our identified QTL $q R L-11$, but here we mapped one more QTL which might be a novel point to find out the role of root length in low phosphorous response. Under $\mathrm{P}+$, only two QTLs were identified for shoot fresh weight on chromosome 1 with LOD value and phenotypic variance $3.32-3.69 \%$ and $2.95-3.68 \%$. No QTLs were detected under $\mathrm{P}-$ and $\mathrm{P}+/ \mathrm{P}-$ for $\mathrm{SFW}$.

Our study had showed contrasting results with previously identified QTLs. Moreover, the root fresh weight is also studied in the current experiment to investigate its role in enhancing low P- tolerance in BRILs. Eight QTLs $q R F W-1, q R F W-3$, and $q R F W-11$ under P-, two on chromosome 1 , five on chromosome 3 and one on 11 with LOD values 20.3 to 21.74 and $5.82 \%$ to $10.74 \%$ of phenotypic variation reported for these. Li et al. (2009) reported two QTLs for root fresh weight with positive additive effect under P-. QTL $q R F W$-3 identified on same chromosome in our study but here 4 more QTLs were identified for root fresh weight in our BRILs seedling traits on chromosome 3 which would facilitate in increasing attention of researchers to target these regions for unfolding low phosphorous tolerance mechanism. Four QTLs for RFW were identified in $\mathrm{P}+$ with LOD value of $10.56-2.86$ and $7.76-1.68 \%$ of phenotypic variance. Six QTLs were identified for RFW, one $(q R F W-1)$ of them is on the chromosome 1 , four 
Table 6 QTLs identified under both condition $\mathrm{P}+/ \mathrm{P}-$ for seedling traits in BRILs

\begin{tabular}{llrlllrrrrr}
\hline Trait & QTLs & Chr & Position & Left Marker & Right Marker & LOD & PVE (\%) & Add & Left CI & Right CI \\
\hline RL & qRL-11 & 11 & 210.50 & bin11-47 & bin11-48 & 6.87 & 19.39 & -1.29 & 208.00 & 214.00 \\
RFW & qRFW-1 & 1 & 372.50 & bin1-114 & bin1-115 & 2.98 & 2.99 & 18.87 & 372.00 & 374.00 \\
& qRFW-3 & 3 & 737.00 & bin3-258 & bin3-259 & 16.54 & 8.55 & -22.67 & 736.50 & 737.50 \\
& qRFW-3 & 3 & 768.00 & bin3-275 & bin3-276 & 14.98 & 8.79 & 18.85 & 765.50 & 769.50 \\
& qRFW-3 & 3 & 771.00 & bin3-276 & bin3-277 & 12.50 & 8.79 & 18.85 & 770.50 & 772.50 \\
& qRFW-3 & 3 & 817.00 & bin3-289 & bin3-290 & 3.01 & 2.74 & 12.85 & 815.50 & 818.50 \\
& qRFW-11 & 11 & 511.50 & bin11-139 & bin11-140 & 21.25 & 14.84 & -24.52 & 510.00 & 515.00 \\
SDW & qSDW-1 & 1 & 218.50 & bin1-72 & bin1-73 & 5.28 & 3.32 & -0.58 & 211.00 & 219.00 \\
& qSDW-1 & 1 & 225.50 & bin1-73 & bin1-74 & 6.20 & 3.39 & -0.55 & 223.00 & 235.00 \\
& qSDW-1 & 1 & 337.50 & bin1-93 & bin1-94 & 2.66 & 1.00 & 0.48 & 336.00 & 339.00 \\
& qSDW-1 & 1 & 356.50 & bin1-102 & bin1-103 & 5.76 & 3.25 & -0.62 & 356.00 & 357.00 \\
& qSDW-1 & 1 & 369.50 & bin1-112 & bin1-113 & 2.56 & 1.00 & 0.48 & 369.00 & 370.00 \\
& qSDW-1 & 1 & 383.50 & bin1-119 & bin1-120 & 18.00 & 6.36 & -0.86 & 383.00 & 385.00 \\
& qSDW-3 & 3 & 730.00 & bin3-254 & bin3-255 & 8.62 & 3.25 & -0.62 & 729.50 & 730.50 \\
& qSDW-3 & 3 & 737.00 & bin3-258 & bin3-259 & 4.58 & 3.25 & -0.62 & 736.50 & 737.50 \\
& qSDW-3 & 3 & 765.00 & bin3-274 & bin3-275 & 5.49 & 3.25 & -0.62 & 764.50 & 765.50 \\
RDW & qRDW-3 & 3 & 730.00 & bin3-254 & bin3-255 & 7.16 & 13.09 & -1.63 & 729.50 & 731.50 \\
\hline
\end{tabular}

RL, root length, RFW, root fresh weight, SDW, shoot dry weight, RDW, root dry weight, Chr, chromosome, LOD, logarithm of odds, PVE (\%), percent of variance explained (\%), Add, Additive effect, CI, confidence interval

$(q R F W-3)$ on chromosome 3 , and one (qRFW-6) on chromosome 6 were detected for RFW with LOD value and phenotypic variation of $2.98-21.25$ and $2.99 \%$ to $14.84 \%$, respectively. Shoot dry weight plays an important role to measure the degree of tolerance under low phosphorous. Two QTLs $q S D W-1$ under $\mathrm{P}-$ and $\mathrm{P}+$ were mapped on chromosome 1 among the bins 1-92, 1-93 and 2.78 and 9.89, LOD value and phenotypic variation recorded for QTL under $\mathrm{P}-$ and $2.64 \mathrm{LOD}$ value and $6.77 \%$ of phenotypic variance for QTL detected under $\mathrm{P}+$.

Many researchers in the past conducted QTL analysis and identified QTLs for shoot dry weight. Li et al. (2009) and Ming et al. (2001) evaluated rice DH lines and IL for QTLs detection under low P and identified one QTL on chromosome 12 and one on chromosome 6 different from our results which might be due to use of different breeding lines. Chromosome one harbor more important regions governing shoot dry weight. Map-based cloning of these points could be more fruitful for MAS selection.

Under $\mathrm{P}-$ and $\mathrm{P}+/ \mathrm{P}-$, two QTLs were detected for RDW on chromosomes 1 and 3. LOD values 3.32 and 7.16 and phenotypic variance $10.24 \%$ and $13.09 \%$ contributed by these QTLs. A total of 12 QTLs based on their position, ten on chromosome 1 , one on 3 and one on 10 chromosomes were detected under $\mathrm{P}+$ level. These QTLs LOD values ranged from 7.77 to 6.90 , and $0.90 \%-1.16 \%$ of variances were noted. Many studied conducted earlier are an agreement with our findings, and some showed contrast because of the difference in breeding material and solution used. Yugandhar et al. (2017) detected 3 QTLs for root dry weight on chromosomes 3,5 and 10 with their phenotypic contribution of 10.82-12.52\%. QTL detected on chromosome 3 is consistent to our identified QTL $q S D W-3$; we have identified one new QTL on chromosome 1 which indicated the possibility of this region to involve in increasing shoot dry weight under $\mathrm{P}$ deficiency tolerance.

Quantitative traits loci mapping for tolerance to low phosphorous will be more useful in the identification of important regions to be cloned for tolerance. In our results, more important indicator of low phosphorous tolerance is shoot length. Among these 50 QTLs, $q S L-3, q R L-11$ were novel QTLs, which would be important to transfer these regions into BRILs for increasing crop growth efficiency under low phosphorous deficient conditions. Two QTLs $q S D W-1$ for secondary tolerance indices like shoot dry weight mapped on chromosome 1 at different regions were newly reported QTLs. One QTL for RDW on chromosome one, $q R D W-1$ is novel QTL, and these traits could also be used for evaluating the degree of low phosphorous tolerance in rice. Many traits showed inter-relationship because of the presence of their QTLs on the same chromosome. Root fresh weight and root dry weight were strongly correlated to each other, and QTLs for these variables were located on the chromosome 1 at same region. Extremely 
Fig. 5 Location of putative QTLs for seedling traits ratio under both level of Phosphorus $\mathrm{P}+/ \mathrm{P}-$, while QTLs displayed in square box, indicates the pleotropic QTLs

\section{Ch1}

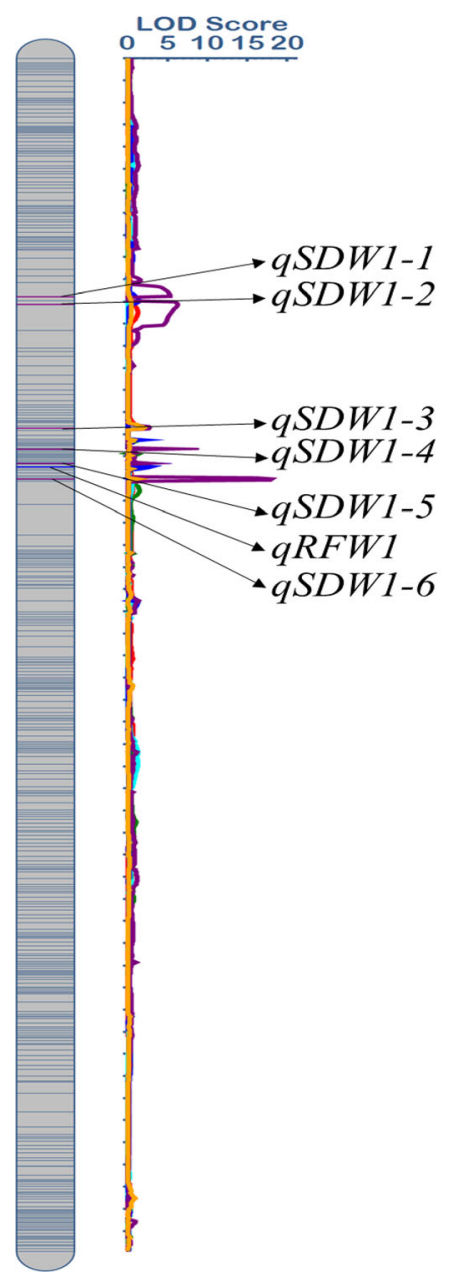

Ch3

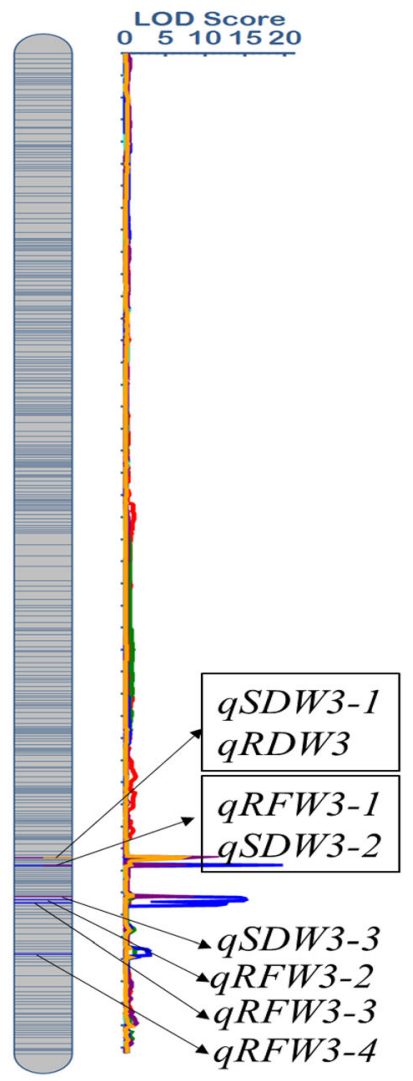

Ch11

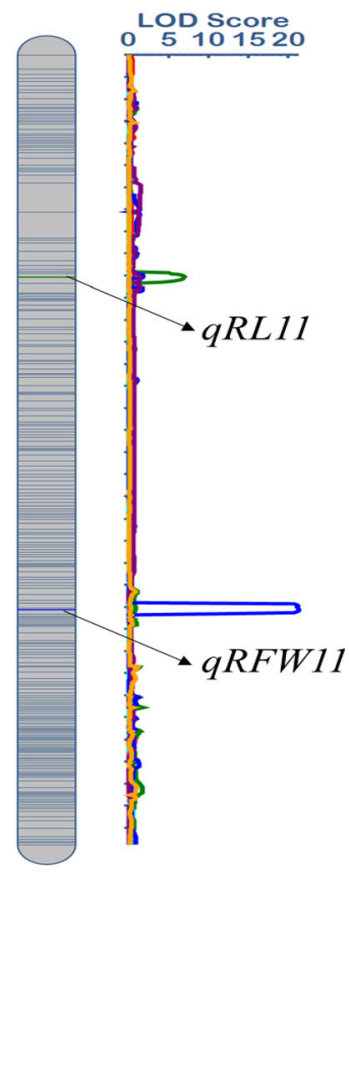

tolerant lines could be used to develop low phosphorous resistant varieties and markers behind these QTLs would be useful to enhance MAS selection for low P tolerance. Effective nutrient solution and nature of population should be more focused to carry out QTL analysis to get insight into low P tolerance mechanism. Identification of 3 pleiotropic QTL, two for SFW and RDW in P+ and one for RFW and SDW in $\mathrm{P}+$ and $\mathrm{P}-$ ratio would be a novel point to isolate these regions and investigate the mechanism of these regions to enhance BRILs tolerance.

\section{Conclusions}

Rice is one of the most important crop of the world, and the presence of abiotic stresses are limiting its growth and ultimately effecting its production. Development of varieties resistant to low phosphorous is an urgent need to maintain rice growth on effected soils. A total of 50 QTLs, 21 under $\mathrm{P}+, 12$ under $\mathrm{P}-$ and 17 under $\mathrm{P}+/ \mathrm{P}-$ for six seedling traits were detected by evaluating 120 BRILs developed from a cross between Japonica (cv.02428) and Indica (Changhui) under two levels of phosphorous $\mathrm{P}+$ and $\mathrm{P}-$. Out of 50 QTLs, major QTLs $q S L-3, q R L-11, q S D W-1$, $q R D W-1$ involved in response to low phosphorus tolerance were novel QTLs. Root fresh weight and root dry weight were strongly correlated to each other, and QTLs for these variables were located on the same chromosome 1 at the same region. Identification of 3 pleiotropic regions is the novelty of our results, and these would be helpful to enhance tolerance via transformation of this locus into BRIL population. These regions would facilitate mapbased cloning to speed up MAS selection for developing low phosphorous tolerant varieties.

Acknowledgements The research was supported by the National Natural Science Foundation of China (Project nos. 31560350 and 31760350) and the Science and Technology Program of Jiangxi, China (Project no. 20171ACF60018), the Key Research and Development Program of Jiangxi Province (20171ACF60018 and 20192ACB60003) and the Jiangxi Agriculture Research System (JXARS-18). 
Author contributions A.M.S wrote the manuscript and performed the experiments. H.K and G.M.W designed the experiment, analyzed the data, and helped to draft the manuscript. A.R, H.R.C and H.X helps in data collection. J.B developed the population. A.A.K, M.S, S.K and M.F revised the manuscript. Z.W and X.P, Project administration and supervised the research work. All authors read and approved the final manuscript.

\section{Compliance with ethical standards}

Conflicts of interest The author declares no conflict of interest.

Open Access This article is licensed under a Creative Commons Attribution 4.0 International License, which permits use, sharing, adaptation, distribution and reproduction in any medium or format, as long as you give appropriate credit to the original author(s) and the source, provide a link to the Creative Commons licence, and indicate if changes were made. The images or other third party material in this article are included in the article's Creative Commons licence, unless indicated otherwise in a credit line to the material. If material is not included in the article's Creative Commons licence and your intended use is not permitted by statutory regulation or exceeds the permitted use, you will need to obtain permission directly from the copyright holder. To view a copy of this licence, visit http://creativecommons. org/licenses/by/4.0/.

\section{References}

Alpuerto V-LEB, Norton GW, Alwang J, Ismail AM (2009) Economic impact analysis of marker-assisted breeding for tolerance to salinity and phosphorous deficiency in rice. Review Agric Econ 31:779-792

Anis G, Zhang Y, Wang H, Li Z, Wu W, Sun L, Riaz A, Cao L, Cheng S (2018) Genomic regions analysis of seedling root traits and their regulation in responses to phosphorus deficiency tolerance in CSSL population of elite super hybrid rice. Int J Mol Sci 19:1460

Bian J, Zhu G, Zhu C, Peng X, Li C, He X, Chen X, Fu J, Hu L, Ouyang L (2015) Molecular dissection of developmental behavior of tiller number and the relationship with effective panicle using indica-japonica introgression lines in rice. Mol Breed 35:91

Byrne S, Czaban A, Studer B, Panitz F, Bendixen C, Asp T (2013) Genome wide allele frequency fingerprints (GWAFFs) of populations via genotyping by sequencing. PLoS ONE 8:e57438

Chao X, Jie R, Xiu-qin Z, Zai-song D, Jing Z, Chao W, Jun-wei Z, Joseph CA, Qiang Z, Yun-long P (2015) Genetic dissection of low phosphorus tolerance related traits using selected introgression lines in rice. Rice Sci 22:264-274

Chin JH, Gamuyao R, Dalid C, Bustamam M, Prasetiyono J, Moeljopawiro S, Wissuwa M, Heuer S (2011) Developing rice with high yield under phosphorus deficiency: pup1 sequence to application. Plant Physiol 156:1202-1216

Dobermann A (2000) Rice: Nutrient disorders \& nutrient management. Int Rice Res Inst

Elert E (2014) Rice by the numbers: a good grain. Nature 514:S50

Gamuyao R, Chin JH, Pariasca-Tanaka J, Pesaresi P, Catausan S, Dalid C, Slamet-Loedin I, Tecson-Mendoza EM, Wissuwa M, Heuer S (2012) The protein kinase Pstoll from traditional rice confers tolerance of phosphorus deficiency. Nature 488:535

Hu B, Wu P, Liao C, Zhang W, Ni J (2001) QTLs and epistasis underlying activity of acid phosphatase under phosphorus sufficient and deficient condition in rice (Oryza sativa L.). Plant Soil 230:99-105
Huang X, Feng Q, Qian Q, Zhao Q, Wang L, Wang A, Guan J, Fan D, Weng Q, Huang T (2009) High-throughput genotyping by whole-genome resequencing. Genome Res 19:1068-1076

Ismail AM, Heuer S, Thomson MJ, Wissuwa M (2007) Genetic and genomic approaches to develop rice germplasm for problem soils. Plant Mol Biol 65:547-570

Jiang N, Shi S, Shi H, Khanzada H, Wassan GM, Zhu C, Peng X, Yu Q, Chen X, He X (2017) Mapping QTL for seed germinability under low temperature using a new high-density genetic map of rice. Front Plant Sci 8:1223

Kumar J, Gupta SD, Gupta S, Dubey S, Gupta P, Kumar S (2017) Quantitative trait loci from identification to exploitation for crop improvement. Plant Cell Reports 36(8):1187-1213

Li J, Xie Y, Dai A, Liu L, Li Z (2009) Root and shoot traits responses to phosphorus deficiency and QTL analysis at seedling stage using introgression lines of rice. J Genet Genomics 36:173-183

Lin DZ, Zhang YJ, Zhang JZ, Luo LJ, Dong YJ (2010) Mapping of QTL for seedling growth response to phosphorus deficiency in rice (Oryza sativa L.). Genom App Biol 29:10-16

Lynch JP (2011) Root phenes for enhanced soil exploration and phosphorus acquisition: tools for future crops. Plant Physiol 156:1041-1049

McCouch SR (2008) Gene nomenclature system for rice. Rice 1:72

Ming F, Zheng X, Mi G, He P, Zhu L, Zhang F (2000) Identification of quantitative trait loci affecting tolerance to low phosphorus in rice (Oryza Sativa L.). Chin Sci Bull 45:520

Ming F, Zheng X, Mi G, Zhu L, Zhang F (2001) Detection and verification of quantitative trait loci affecting tolerance to low phosphorus in rice. J Plant Nutr 24:1399-1408

Ni J, Wu P, Senadhira D, Huang N (1998) Mapping QTLs for phosphorus deficiency tolerance in rice (Oryza sativa L.). Theor Appl Genet 97:1361-1369

Poland JA, Brown PJ, Sorrells ME, Jannink J-L (2012) Development of high-density genetic maps for barley and wheat using a novel two-enzyme genotyping-by-sequencing approach. PLoS ONE 7:e32253

Richardson AE, Hocking PJ, Simpson RJ, George TS (2009) Plant mechanisms to optimise access to soil phosphorus. Crop Pasture Sci 60:124-143

Sonah H, Bastien M, Iquira E, Tardivel A, Légaré G, Boyle B, Normandeau É, Laroche J, Larose S, Jean M (2013) An improved genotyping by sequencing (GBS) approach offering increased versatility and efficiency of SNP discovery and genotyping. PLoS ONE 8:e54603

Vinod KK, Heuer S (2012) Approaches towards nitrogen- and phosphorus-efficient rice. AoB Plants 2012:Pls028

Wang L, Wang A, Huang X, Zhao Q, Dong G, Qian Q, Sang T, Han B (2011) Mapping 49 quantitative trait loci at high resolution through sequencing-based genotyping of rice recombinant inbred lines. Theor Appl Genet 122:327-340

Wang K, Cui K, Liu G, Xie W, Yu H, Pan J, Huang J, Nie L, Shah F, Peng S (2014) Identification of quantitative trait loci for phosphorus use efficiency traits in rice using a high density SNP map. BMC Genet 15:155

Wang X, Yu K, Li H, Peng Q, Chen F, Zhang W, Chen S, Hu M, Zhang J (2015) High-density SNP map construction and QTL identification for the apetalous character in Brassica napus L. Front Plant Sci 6:1164

Wissuwa M, Yano M, Ae N (1998) Mapping of QTLs for phosphorusdeficiency tolerance in rice (Oryza sativa L.). Theor Appl Genet 97:777-783

Wissuwa M, Wegner J, Ae N, Yano M (2002) Substitution mapping of Pup1: a major QTL increasing phosphorus uptake of rice from a phosphorus-deficient soil. Theor Appl Genet 105:890-897

Xie W, Feng Q, Yu H, Huang X, Zhao Q, Xing Y, Yu S, Han B, Zhang Q (2010) Parent-independent genotyping for constructing 
an ultrahigh-density linkage map based on population sequencing. Proc Natl Acad Sci 107:10578-10583

Xu J, Zhao Q, Du P, Xu C, Wang B, Feng Q, Liu Q, Tang S, Gu M, Han B (2010) Developing high throughput genotyped chromosome segment substitution lines based on population wholegenome re-sequencing in rice (Oryza sativa L.). BMC Genom 11:656

Yoshida S, Forno DA, Cock JH (1971) Laboratory manual for physiological studies of rice Laboratory manual for physiological studies of rice

Yugandhar P, Basava RK, Desiraju S, Voleti SR, Sharma R, Neelamraju S (2017) Identifying markers associated with yield traits in Nagina22 rice mutants grown in low phosphorus field or in alternate wet/dry conditions. Aust J Crop Sci 11:548

Zhang Y, Dong Y, Zhang J, Xiao K, Xu J, Terao H (2006) 14. Mapping QTLs for deficiency phosphorus response to rootgrowth of rice seedling. Rice Genet News 25:36-37

Zhang Y, Anis GB, Wang R, Wu W, Yu N, Shen X, Zhan X, Cheng S, Cao L (2018) Genetic dissection of QTL against phosphate deficiency in the hybrid rice 'Xieyou9308'. Plant Growth Regul $84: 123-133$

Publisher's Note Springer Nature remains neutral with regard to jurisdictional claims in published maps and institutional affiliations. 